УДК $338.242+323.2$

JEL D79, Z18, A13

$10.17213 / 2075-2067-2019-4-25-35$

\title{
АНАТОМИЯ РОССИЙСКОГО ЛИБЕРАЛИЗМА: «НОВАЯ НОРМАЛЬНОСТЬ» ГЛОБАЛИЗАЦИИ И ЗАДАЧИ ИМПОРТОЗАМЕЩЕНИЯ СОЦИАЛЬНЫХ ИНСТИТУТОВ1
}

\section{(C) 2019 г. P. М. Нижегородцев}

\section{Институт проблем управления РАН, г. Москва}

Статья посвящена анализу современного российского либерализма в различных его проявлениях в связи с глобализационными тенденцииями мировой экономики. Отдельное внимание уделено импорту социальных институтов в современной России и обоснованию необходимости их импортозамещения. Обсуждаются также задачи экономического роста для России и ограничения, стоящие на этом пути.

Ключевые слова: либерализм; социальные институты; экономика России; импортозамещуение; глобализачия; экономическая безопасность.

The article is devoted to the analysis of modern Russian liberalism in its various manifestations in connection with the globalization trends of the world economy. The special attention is paid to the import of social institutions in contemporary Russia and the reasons for their import substitution. The problems of economic growth for Russia and the limitations in this way are also discussed.

Key words: liberalism; social institutions; Russian economy; importsubstitution; globalization; economic security.

\section{И интереснее всего в этом вранье то, - сказал Воланд, - что оно - вранье от первого до последнего слова.}

М. Булгаков

\section{Вместо введения}

Для начала констатируем тот факт, что некоторая часть российской интеллигенции до сих пор произносит слово «либерализм» с томным и мечтательным выражением лица, возлагая на этот тип общественного устройства определенные надежды, хотя перспективы того, что они оправдаются, весьма сомнительны. Казалось бы, опыт либерализации экономики (да и политики) в России и в ряде соседних с нами стран должен был давно остудить пыл приверженцев либеральной до- ктрины, но еще больше почвы для сомнений на ее счет дает практика развития западных стран, поднимающих эту доктрину на щит и громко объявляющих себя ее носителями.

Либерализм - это система, где лошади предоставляется право выбрать кнут, которым ее хлещут. Но при этом лошадь остается лошадью, кучер - кучером, а конюх - конюхом, они никак не поменяются местами. Курица вправе выбрать нож, которым ее зарежут, хотя и здесь выбор из довольно ограниченного набора вариантов.

1 Работа выполнена при частичной поддержке Российского фонда фундаментальных исследований (проект №17-02-00586a-ОГН). 
Суть капиталистической демократии, как писал Маркс, заключается в том, что угнетенным раз в несколько лет позволяют решать, какой именно из представителей угнетающего класса будет в парламенте представлять и подавлять их $[1,2]$.

Либерализм - это система, при которой Великобритания, ведущая войну в Северной Ирландии, истребляет четверть населения этой страны вполне либеральным образом. Это система, при которой англо-американские войска, находясь на границе между Сербией и Хорватией, обстреливают Сербию и Хорватию, уверяя при этом, что это они, сербы и хорваты, стреляют друг в друга, а натовские войска на этой территории нужны лишь затем, чтобы обеспечить мир и безопасность. А потом те же англо-американские войска бомбят и Сербию, и Хорватию, уверяя, что это необходимо для поддержания мира. Впоследствии официальные лица вполне либерально признают, что это наглая, чудовищная ложь, но эти признания уже никого не спасут.

Либерализм - это система, при которой городская газета печатает портрет президента в траурной рамке за день до его приезда в город, где он будет убит. А репортеры, приезжая в другую страну, дружно съезжаются в один и тот же город и снимают номера в гостиницах с видом на одну и ту же площадь, где через два дня должны состояться стихийные, абсолютно неконтролируемые выступления оппозиции, а затем строго за полчаса до их предполагаемого начала дружно направляют туда видеокамеры.

Быть может, кому-то кажется, что либерализм - это идеал общественного устройства. Эта точка зрения тоже имеет право на жизнь. Нужно лишь ясно отдавать себе отчет в том, что такое либерализм, и смотреть на него открытыми глазами, без розовых очков, не приписывая ему функций, на выполнение которых он в принципе неспособен.

Забавно, что если отбросить двойные стандарты и забыть об исключительности роли отдельных стран в мировой политике, то быстро выяснится, что Соединенные Штаты Америки имеют ничуть не больше прав на существование в качестве самостоятельного государства, чем, например, Донецкая Народная Республика. Разница между ними заключается только в том, что США достигли мощи, с которой нельзя не считаться на международном уровне, а ДНР до подобных успехов пока далеко.

В свое время сепаратисты, объявившие о независимости США от Великобритании, грубо нарушили существовавшие на тот момент законы Британской империи. А если применить к тогдашнему населению США ценз оседлости наподобие того, который вполне либеральным образом существует сегодня в прибалтийских республиках и позволяет их правительствам отличать «граждан» страны от «неграждан», в основной своей массе являющихся потомками «некоренного» населения этих стран, то численность людей, которые были бы вправе решать вопросы государственного устройства Самопровозглашенных Штатов Америки, и вовсе свелась бы к количеству потомков краснокожих индейцев.

Кстати, я нередко задаю вопрос коллегам, настаивающим на соблюдении норм толерантности и политкорректности: почему они считают слово «негр» (или «черный») оскорблением и неполиткорректным названием представителей африканской расы, а слово «белый» применительно к представителям европейской расы оскорблением не считают? T.е. назвать черного черным - оскорбительно, а назвать белого белым - это нормально, это в порядке вещей. Вот эта точка зрения и есть замаскированный расизм, это молчаливое признание того, что белые являются высшей расой.

\section{1. Антиномии современного либера- лизма и глобализация}

В социальной политике либерализм противостоит патернализму. В удовлетворении жизненных потребностей агенты полагаются либо преимущественно на свои усилия, либо на волю государства, обеспечивающего их необходимыми благами. Например, после очередных террористических актов всегда усиливаются голоса патерналистов, призывающих правительство ужесточить меры контроля, досмотра и т.п. Им противостоят либералы, которые говорят, что не согласны с тотальной слежкой, обысками, прослушиваниями, проверками и т.д., не потерпят усиления контроля над частной жизнью и впол- 
не осознают вытекающий из этого риск. Спор между этими точками зрения бесконечен, и в демократическом обществе мнение большинства граждан о степени допустимости вмешательства государства в частную жизнь является определяющим.

В экономической политике либерализм противостоит дирижизму. Степень регулируемости экономики может быть различной в зависимости от многих причин, в том числе от фазы промышленного цикла, на которой находится экономика в данный момент. Дирижисты настаивают на усилении вмешательства государства в хозяйственную жизнь, что обычно выражается в росте налогов и государственных инвестиций, а также госрасходов. Либералы настаивают на снижении роли государства и стимулировании частной инициативы. Спор между либералами и дирижистами тоже бесконечен, но вопросы экономической политики даже в самом демократическом обществе не решаются голосованием, это удел профессионалов. Поэтому споры такого рода разрешаются в зависимости от позиций господствующих в данный момент экономических доктрин. С точки зрения экономической теории, вопрос о наилучшем способе стимулирования экономического роста (или обеспечения максимально «мягкой» посадки во время кризиса) и о роли государства в этих процессах выражается так называемой альтернативой Хаавельмо [3, 4].

К этим классическим воззрениям на либерализм в социальной и экономической политике в наши дни прибавляется еще одно измерение, тесно связанное с вызовами современной глобализации. Либералами называют себя люди, выступающие за максимальное снижение барьеров входа на рынки, за снижение количества неторгуемых благ, за унификацию социальных и экономических институтов и тем самым объективно поддерживающие глобализацию в том виде, в котором она навязывается мировому хозяйству глобальной финансовой олигархией, ядром базирования которой выступают США.

Еще раз подчеркнем, что глобализация это экспорт социальных и экономических институтов, сформированных и поддерживаемых наиболее богатыми и развитыми странами мира, осуществляемый в геополитичес- ких, геоэкономических и военно-стратегических интересах этой группы стран [5].

Основные инструменты современной глобализации таковы.

1. Монополизация прав на создание соответствующей системы институтов, на формирование правил поведения. Основным пособником США в этом процессе служит система спонсируемых ими международных регулирующих организаций, обеспечивающих стандартизацию во всех сферах - от промышленности до спортивной медицины.

2. Отсюда частично вытекает второй инструмент глобализации, мирового экспорта институтов - это применение юрисдикции США вне ее территориальных пределов. В этом смысле кровавое вторжение США на территорию Панамы в 1989 году, в результате которого экономика этой страны была разрушена, американский доллар стал в ней официальным платежным средством, а США обрели контроль над Панамским каналом, мало чем отличается от околофутбольного скандала с ФИФА в 2015 году, в результате которого Соединенные Штаты смогли заблокировать ряд невыгодных для себя решений, принятых чиновниками этой организации.

3. Претензии на мировое господство или, по крайней мере, лидерство, миссионерские наклонности, отождествление себя с цивилизованным миром. Представление самих себя в качестве носителей «общечеловеческих ценностей». Американские военные базы разбросаны сегодня по всему миру, и даже названия управлений армии США, поделивших весь земной шар на зоны, свидетельствует о готовности этой страны вмешаться в события, происходящие в любой части планеты.

4. Переоценка исторических событий в пользу США, переписывание истории, вплоть до прямых подтасовок фактов и статистики, с целью придания США более значительной и более привлекательной роли в мировой истории. Стоит ли и говорить о том, что подобное вранье, на котором специализируются западные историки, направлено на искажение и принижение роли основных конкурентов США, как это происходит, в частности, с историей Второй мировой войны и касается и ее причин, и итогов, и последствий.

5. Разработка и апробация по всему миру определенных социальных технологий. 
В последнее время на примере процедуры лишения олимпийских медалей апробируется технология, основанная на трех ключевых составляющих: подмена тезиса, презумпция виновности, коллективная ответственность. Аналогичная технология лежит в основе процедуры лишения ученых степеней [6], неплохо отработанной в современной России и нередко проводимой на основании заявлений о лишении ученых степеней, содержащих в том числе и заведомо ложные сведения.

Похожая, но не тождественная ей технология апробируется на примере многочисленных обвинений в так называемом харрасменте: это крайне удобный способ расправы с кем угодно, ибо данная технология предполагает презумпцию виновности: бремя доказательств лежит на обвиняемом, а обвинителю верят на слово, что радикально нарушает логику современного права.

6. Контроль над глобальными финансовыми потоками. Сюда относится как глобализация финансовых рынков, так и применение инструментов внешнего долга, обеспечивающих формирование «долговой петли», которая привязывает правительство страны-должника к западным центрам принятия решений.

7. Формирование транснациональных цепочек создания ценности, основанное на импорте промежуточных и экспорте конечных продуктов. В результате возникают глобализированные дилерские сети, пронизывающие весь земной шар, а рынки захватывают транснациональные корпорации, выкачивающие добавленную стоимость из развивающихся стран, в которых базируются промежуточные звенья созданных цепочек и потребители продукции этих компаний.

8. Организация вооруженных вторжений в другие страны, свержение неугодных национально ориентированных правительств и насаждение марионеточных режимов. Тот факт, что во главе оккупированной страны при этом неизменно оказывается местный компрадор и коллаборационист, не отменяет факта оккупации этой страны и ее прямого подчинения зарубежным центрам принятия решений. Задача оккупационной администрации как раз и заключается в том, чтобы обеспечить режим прямого внешнего управления собственной страной.
В ряде случаев вооруженное вторжение в те или иные страны маскируется при помощи организации так называемых «цветных революций». Для того чтобы обеспечить ее успех, необходимо провести несколько этапов подготовительной работы.

А. Вербовка агентов из числа лиц, принимающих решения (чиновников различных уровней), представителей средств массовой информации (печатных и электронных), а также медийных, популярных, узнаваемых в стране личностей, готовых в нужный момент выступить в роли ангажированных «экспертов» или призвать к определенным действиям.

Б. Формирование команды так называемых оппозиционных политиков и рядовых организаторов мятежа, способных организовать и скоординировать действия больших групп людей.

В. Создание штурмовых бригад (бандформирований), готовых в нужный момент осуществить силовые действия преступного характера.

Одним из подготовительных этапов может стать разработка бренда оппозиционных действий. Это может быть определенный лозунг, цвет, девиз, хорошо узнаваемый и привлекательный символ, благодаря которому сторонники мятежа могли бы узнать друг друга, а его организаторы - сформировать медийное пространство вокруг данного символа.

После того как эти задачи решены, начинается собственно цветная революция, мятеж, подлинные организаторы которого находятся за рубежом. Сам мятеж также проходит в несколько этапов.

А. «Онижедети». Этап бессмысленных жертв. Одно из лиц, принимающих решения, отдает приказ о силовом подавлении некоего провокационного выступления, имеющего хотя бы косвенное отношение к так называемым оппозиционным силам, например, протестующего против принятия очередного закона или проведения каких-либо преобразований, инициатором которых выступает действующее правительство. Чем более бессмысленным и кровавым будет это событие, чем более многочисленны его жертвы, тем лучше с точки зрения конечного успеха.

После этого начинается истерия в подконтрольных мятежникам средствах массовой информации, в этих СМИ выступают так 
называемые независимые эксперты и просто медийные личности, выдвигающие версии о причастности правительства или президента к реализованной провокации и призывающие их уйти в отставку.

Б. «Палаточные бомжи». На волне так называемого народного протеста и народного гнева (хотя сам народ может не иметь к нему никакого отношения) возникает палаточный городок (бессрочная акция протеста), населяемый специально привезенными для этой цели бомжами, деклассированными элементами, готовыми за бесплатную бутылку водки или за бесплатную дозу жить неделями в этом городке. В это палаточное сообщество время от времени наведываются медийные фигуры, дабы сделать красивую картинку в телеэфире и создать видимость участия широких слоев населения в организованном таким образом протесте.

За это время решается еще одна важная вспомогательная задача - частичная деморализация силовых структур, гарантирующая их переход на сторону мятежников или, в крайнем случае, их отказ участвовать в подавлении мятежа. Когда данная задача решена, наступает завершающий этап.

В. Силовая операция по отстранению от власти. В это время специально подготовленные и обученные бандформирования идут на захват правительственных зданий, блокируют сопротивляющихся представителей власти и обеспечивают силовой захват властных структур - проведение внеочередных выборов, заседаний, съездов и т.д., ключевую роль в которых будут играть борющиеся за захват власти мятежники.

На этом этапе обеспечивается медийная поддержка, тиражирующая мнение о нелегитимности действий законной власти и о законности и правомерности преступных действий борющейся за власть оппозиции.

Как видим, последовательность действий, сценарий, по которому проходит «цветная революция», в разных странах совершенно одинаков, он определяется социальной технологией, лежащей в его основе.

\section{2. Российские реальности: мимикрия} либерализма

Проведенные рассуждения подчеркивают тот факт, что сегодня проекту однополяр- ного мира, во главе которого стоит мировая финансовая олигархия, во многом сросшаяся с американской политической, экономической и военной верхушкой, противостоит проект многополярного мира, который возглавляют национальные государства - центры силы.

Борьба между сторонниками этих двух проектов происходит внутри практически каждой страны, но в развивающихся странах (пребывающих в инфляционном разрыве), включая Россию, эта борьба острее и заметнее [7]. В этих странах либерализму, отстаивающему интересы мировой олигархии, противостоит патриотизм, олицетворяющий интересы значительной части национального капитала, заинтересованного в укреплении национального государства.

Внутри самой России национально ориентированному капиталу противостоит компрадорский капитал, зависимый от интересов глобальной финансовой олигархии, и противоречие между ними объективно, оно вытекает из различия условий, необходимых для самовозрастания разных частей национального капитала. В странах «мировой периферии» данное противоречие очень типично: часть национального капитала заинтересована в укреплении национального государства, с которым она в значительной мере срослась (и она формирует соответствующие институты), другая часть делает ставку на победу транснационального капитала и способствует импорту в собственную страну институтов, которые ее разрушают. Это «пятая колонна», заинтересованная в демонтаже институтов государственности своей страны.

Современный либерализм в России мимикрирует, он поднимает на щит «общечеловеческие ценности», маскирует свои устремления под магистральный путь развития цивилизации, но есть определенные знаковые моменты, позволяющие безошибочно выявить, распознать позицию либерализма. Кратко их перечислим.

1. Проведение работы по демонтажу институтов государственности (как в форме ослабления этих институтов, так и в виде чрезмерной их бюрократизации, что проявляется, в частности, в реформах сфер науки, образования, здравоохранения, проводимых в последние 10 лет). Это приводит к много- 
численным призывам вывести соответствующие сферы из-под опеки государства или передать на аутсорсинг в частные руки - желательно за рубеж.

В связи с этим можно напомнить, что программу приватизации в России в начале 90-х годов сделала американская консалтинговая компания по заказу российского правительства, а также вспомнить знаменитую фразу одного из российских министров тех лет: «зачем России собственная внешняя политика? в Вашингтоне это делают лучше».

Сюда же относится и преклонение перед Западом в любой форме и во всех его проявлениях. Призывы сделать у нас «как там», вернуться к магистральному пути развития человечества, и прочие обывательские пошлости, заменяющие лозунгами научный анализ. Попытки поставить западные страны в пример России, даже в том, в чем очевидно наше превосходство, - например, в организации сферы науки и ее результативности. Обеспечение импорта институтов из стран Запада (прежде всего США) в Россию. Преувеличение угрозы так называемых санкций, вводимых западными странами против России, и ущерба от этих санкций для российской экономики.

Одна из популярных в наши дни форм преклонения перед Западом - насаждение мифов о либеральном устройстве экономики и политической системы западных стран. На самом деле экономика России многократно либеральнее любой из них. Доля ВВП, перераспределяемая через бюджеты всех уровней, в современной России вот уже 30 лет не превышает $20 \%$, и даже в период послевоенного восстановления экономики (период максимальной концентрации экономической власти государства и аллокации ресурсов за счет усилий государственной власти) эта доля не превышала 36-37\%. На сегодняшний день доля ВВП, перераспределяемая через госбюджет, в любой развитой стране выше, чем в России, и наиболее высока она в скандинавских странах - 55$58 \%[8,9]$. Доля товарного ассортимента, на который устанавливаются фиксированные цены, в современной России не превышает $12 \%$, эта доля наиболее высока в Германии - 26-27\%. В России частным лицам предоставляется возможность быть собс- твенниками оружейных магазинов и аптек с неограниченным ассортиментом лекарственных препаратов, разумеется, при наличии лицензии от государства, тогда как в подавляющем большинстве стран ЕС их собственником может быть только государство. Россия проводит наиболее открытую миграционную политику, наводняя свой рынок труда иностранцами, тогда как в любой развитой стране существует жесткая система квот, формирующая административные барьеры входа на национальные рынки труда.

Демонтаж институтов государственности иногда проявляется в создании параллельных управленческих структур (например, ФАНО), блокирующих управленческие воздействия и дезорганизующих управление целыми сферами жизни страны.

2. Попытки опорочить страну, ее руководство, народ и его ценности.

Сюда относятся, прежде всего, разные дурацкие клише, которыми изобилуют как псевдонаучные западные источники, так и западная пресса: Россия - страна дураков, русские все алкаши, Россией правят дураки или негодяи и т.п. Призывы извиниться за то, что мы русские, и покаяться в том, в чем нас безосновательно обвиняют. Разговоры о том, что мы неспособны ничего сделать, нам не нужна новая техника, как папуасам, - мы просто не сумеем на ней работать. Не нужны нам мегапроекты вроде проведения олимпиады и чемпионата мира по футболу, это другим странам выгодно, а для нас одни убытки, потому что мы не сумеем этим воспользоваться, и т. д. Экономическая практика всякий раз опровергает подобные выводы, однако эти разговоры не прекращаются, ибо находятся силы, подпитывающие данный набор тезисов с известной регулярностью.

К этому же пункту относятся умственные упражнения определенной части так называемой российской интеллигенции, которая пишет книги и снимает фильмы, паразитирующие на штампах, усердно вбиваемых в голову западному обывателю. Разумеется, подобные произведения так называемого искусства не могут остаться без внимания западных критиков, они изначально сделаны ради того, чтобы снискать их расположение, как бы на экспорт. Хороший пример такого рода фильм «Левиафан» Андрея Звягинцева. 
Это типичный импорт институтов (шаблонов, рутин, образцов поведения), пытающихся ниспровергнуть или оболгать нравственные ценности русского народа. Когда читаешь высказывания о том, что русская национальная идея заключается в силе, наглости и хамстве, их даже нет смысла опровергать. Как сказано в одной очень неглупой книге, написанной более пяти тысяч лет назад, мы видим вещи не такими, какие они есть, а такими, какие мы есть. Книга называется «Талмуд».

3. Искажение истории, подтасовка фактов.

Основные усилия направляются на то, чтобы опорочить и развенчать советский период отечественной истории. Заметим, что атака на советский строй предпринимается западными историками и политологами с завидным постоянством. Вспомним хотя бы смешную дискуссию о том, был ли залп «Авроры», давший сигнал к штурму Зимнего дворца, или его не было. Отрицание его наличия базируется на том факте, что в начале штурма Зимний дворец был совершенно целым и нисколько не пострадал от залпа артиллерийских орудий, хотя в любом учебнике написано, что «Аврора» стреляла холостыми, и задача разрушить Зимний дворец просто перед ней не стояла.

Особенно дерзкие и абсурдные искажения истории со стороны как западных историографов, так и озвучивающих их изыскания на русском языке отечественных либералов касаются подвига советского народа в Великой Отечественной войне. Сюда относится и откровенная ложь о том, что не было подвига 28 героев-панфиловцев (в пользу этой версии свидетельствует откровение одного из высокопоставленных военных, находившегося в тот момент крайне далеко от места сражения, против - десятки задокументированных исторических свидетельств как военнослужащих, так и мирных жителей, непосредственно этот бой наблюдавших), и версии о том, что Зоя Космодемьянская молчала на допросе вследствие того, что была умственно отсталой, а Александр Матросов, закрывший грудью амбразуру вражеского дзота, просто поскользнулся.

В работах западных историографов и российских либералов советская армия, освободившая пол-Европы от фашистского рабства, объявляется оккупационной, а ос- вобождение даже территории собственной страны - Советского Союза - представляется как российская оккупация союзных республик. На этом основании коммунистическая идеология приравнивается к фашистской, и в ряде постсоветских стран происходит так называемая декоммунизация, направленная на максимальное отдаление от России.

Неприятие советского периода истории России выражается также в неумном восхвалении дореволюционного периода. Это происходит под видом «возвращения» якобы незаслуженно забытых или недооцененных деятелей данного периода, например, канонизации Николая Второго и возвеличивании Столыпина (кстати, они оба - фигуры более чем спорные с точки зрения их роли в истории российского государства), а также возвращения исторических названий топонимов - прежде всего улиц и населенных пунктов (Санкт-Петербург, например). Такое мнимое имперство является не чем иным, как вывернутым наизнанку либерализмом.

К этому же пункту относится забвение или отрицание роли России и СССР в мировой истории, когда ставятся под сомнение очевидные, хорошо известные и многократно проверенные факты (например, факт решающей роли Советского Союза в победе над фашистской Германией или факт полета Гагарина в космос), а также замалчивание или отрицание очевидных достижений России последних 20 лет, воспевание и идеализация «святых 90-х», столь характерные для западной прессы.

4. Последовательная защита прав и интересов различных меньшинств.

Российские либералы готовы поддерживать кого угодно, если они выступают против правительства, ориентированного на реализацию национальных интересов. В частности, они поддерживают всевозможные провокации вроде проведения гей-парадов. Запрет на их проведение трактуется как подавление демократических свобод. Но в подлинно демократическом обществе именно большинство граждан решает, что является свободой, а что - нарушением общественного порядка. Если, например, большинство населения выскажется за то, что ходить голыми по улицам - это нормально, то запрет на пребывание обнаженным в общественных местах 
станет подавлением свобод. А до тех пор, пока это не так, желающие прогуляться в голом виде должны с этим считаться и не навязывать большинству свою точку зрения. Они могут реализовать свое право в частной, непубличной среде (скажем, у себя дома) либо в специально отведенных для этого местах (нудистские пляжи, например).

Сюда же относится поддержка феминизма и организация травли неугодных либералам публичных личностей на основании обвинений в домогательствах (харрасменте), а также организация публичных провокаций вроде выступления Pussy Riot в православной церкви. При этом весьма характерны попытки представить точку зрения меньшинства в качестве доминирующей, наиболее распространенной позиции, например, выдать проплаченные митинги так называемой оппозиции за народные протесты.

5. Попытки разделить страну и ее население по любому признаку, доказать, что интересы и ценности одной ее части несовместимы с интересами и ценностями других частей.

Это могут быть попытки разделить страну по имущественному признаку, по профессиональному (разделение на банкиров и оленеводов), конфессиональному (поддержка сепаратистских движений, возникающих на религиозной почве) и проч.

В последние годы популярно разделение по интеллектуальному признаку: 90\% населения не покажут на карте Крым, присоединение которого они так горячо поддерживают; 80\% населения всего мира - идиоты, и т.д. При этом те, кто формулирует это разделение, естественно, причисляют самих себя к интеллектуальному меньшинству.

Отдельная группа угроз исходит от попыток разделить страну по территориальному, географическому принципу. Это, в частности, повторение призыва Б. Ельцина, обращенного к российским регионам: берите столько суверенитета, сколько сможете унести; при этом остается открытым, собственно, ключевой вопрос: а куда его унести?

Сюда же относится и позиционирование отдельной национальности - сибиряк, всевозможные разговоры о том, что жители Сибири и Дальнего Востока не такие, как эти европейские русские. Позиционирова- ние Калининграда как Кенигсберга, попытки возвращения «исторических» (т.е. немецких) топонимов в этом городе и продвижение его европейской исключительности, отличий от якобы более отсталой «материковой» России. Продвижение идей Баренц-региона, многочисленные атаки на российский суверенитет над арктическими территориями и призывы поставить их под международный контроль, усилившиеся в последнее время в связи с оживлением Северного морского пути [10]. Наконец, сюда же относится традиционное и уже набившее оскомину противопоставление Москвы и остальной территории страны.

Основной целью всех этих многочисленных информационных атак, разделений и противопоставлений является подрыв территориальной целостности Российской Федерации и введение внешнего управления на ее обломках.

Угрозы, исходящие от подобных воззрений и от их носителей, нужно вовремя распознавать. Если мы не хотим потерять страну в результате либерального реванша, нужно срочно менять парадигму кадровой политики, обеспечивая импортозамещение социальных институтов.

\section{3. Задачи экономического роста для России}

Прежде всего заметим, что в современной экономике России действует множество факторов, ограничивающих внутренний спрос.

В первую очередь, это импортируемые институты монетарной политики [11, 12], предполагающие сжатие денежной массы, дефицит длинных денег и вывоз капитала из страны в первую очередь правительством и Центробанком, обеспечивающими вложение относительного излишка бюджетных средств в покупку гособлигаций США. Сюда же относится и чрезмерная закредитованность населения, обостряющая проблему «плохих» кредитов и чреватая массовыми банкротствами, а также готовящиеся правительством меры по борьбе с теневой экономикой и снижению ее доли в валовом выпуске страны.

Во вторую очередь, это социальная политика, основанная на поддержании дешевизны 
труда как одного из конкурентных преимуществ российской экономики. Асоциальная политика такого рода приводит к многочисленным неблагоприятным последствиям для экономики страны - прежде всего тем, что она провоцирует развитие маргинального рынка труда в ущерб элитарному и блокирует создание высокооплачиваемых рабочих мест, обеспечивая отток квалифицированных кадров за рубеж [13].

Наконец, в третью очередь, это экспорт благ с низкой добавленной стоимостью, к которому приводит реализация лозунга встраивания в глобальные технологические цепочки, что в условиях становления цифровой экономики в мировом хозяйстве создает угрозы экономической безопасности страны $[14,15]$.

Первоочередные меры, которые позволят в известной степени демпфировать возникающие угрозы, таковы.

1. Импортозамещение благ. Наиболее успешно эти процессы на сегодняшний день идут в сельском хозяйстве и в сфере транспортных услуг. Сюда относится, в частности, создание мощных грузовых и нефтяных терминалов на территории Ленинградской области, оставляющее не у дел аналогичную транспортную инфраструктуру прибалтийских республик, а также оживление Северного морского пути, позволяющее удешевить и ускорить доставку грузов, а заодно уйти от проблемы африканских пиратов, наличие которых позволяет британским страховым компаниям постоянно взвинчивать цены на услуги страхования грузов.

Заметим, что в тех секторах, которые успешно осуществляют импортозамещение, активно развивается и экспортная ориентация. В современной экономике эти два направления не альтернативны по отношению друг к другу, а взаимно обуславливают и дополняют друг друга, как показывают, в частности, результаты имитационного моделирования российской экономики [16].

2. Импортозамещение институтов, необходимость которого была ранее обоснована достаточно подробно [17, 18].

3. Обеспечение выпуска конечных наукоемких продуктов: формирование в наукоемких отраслях предприятий, выступающих системными интеграторами, аккумулирую- щими добавленную стоимость, создаваемую в глобальных технологических цепочках, и обеспечивающими контроль над ними.

4. Разработка и применение высоких управленческих технологий, в том числе социальных технологий и (может быть, в первую очередь) технологий стратегического планирования экономики и социальной сферы.

Анализ данного вопроса был бы неполон без упоминания о том, что импортозамещение институтов губительной экономической политики означает в том числе разоблачение абсурдных теоретических воззрений, лежащих в ее основе.

\section{Вместо заключения}

Некоторые коллеги выражают недоумение (а то и негодование) по поводу того, почему популярность экономической теории резко упала, почему к теории все реже обращаются как в учебном процессе (при изучении других экономических дисциплин), так и в принятии практических решений. Мне представляется, что ответ на этот вопрос очевиден. Главная причина в том, что под видом экономической теории преподается (и изучается) только и исключительно неоклассический синтез, причем, как правило, в его наиболее клиническом либеральном варианте.

Т.е. студентам рассказывают, что идеальным и желаемым состоянием экономических систем является равновесие, что невидимые руки и прочие части тела обеспечивают равенство спроса и предложения на локальных рынках, что Парето-эффективное состояние макросистемы гарантирует оптимальное распределение ресурсов, что объем инвестиций должен быть равен объему сбережений, что задача государства - охранять правомочия и компенсировать провалы рынка. Нормальных людей давно уже тошнит от этого либерального вранья, сопровождаемого лозунгами в духе laissez faire.

Это абсурдный, политически и социально ангажированный и попросту лженаучный вариант экономической теории, который массово тиражируется учебниками и порождает губительные и абсурдные решения в экономической политике стран, правительства которых внимают либеральным сентенциям так называемых экспертов из организаций 
вашингтонской шестерки (шестерки в любом смысле этого слова), прежде всего Международного валютного фонда и Международного банка реконструкции и развития.

С тех пор как Россия импортировала эту доктрину в качестве ведущей и единственно возможной, разговоры о деидеологизации экономической науки прекратились. Очевидно, их целью было не освобождение экономической теории от влияния какой бы то ни было идеологии, а замещение одной (коммунистической) идеологии другой (либеральной). Вместе с этим замещением оказалась выброшена за борт марксистская методология экономического анализа, обеспечивающая диалектико-материалистический взгляд на развитие социальных систем и на динамику их внутренних противоречий.

На сегодняшний день Россия находится на пороге импортозамещения данного института - либеральной экономической доктрины, причем как в теории, так и в экономической политике. От успешности и своевременности данного процесса зависят перспективы развития страны, ее экономическая безопасность и территориальная целостность.

\section{Литература}

1. Маркс K. Гражданская война во Франции // Маркс К. и Энгельс Ф. - Соч. 2-е изд. - Т. 17.

2. Ленин В. И. Государство и революция // Полн. собр. соч. 5-е изд. - Т. 33.

3. Нижегородиев Р. М. Альтернатива Хаавельмо: управление мультипликационными эффектами // Социальная экономика в условиях цивилизационных перемен в современном мире: парадигмы и векторы развития: Материалы международной научно-практической конференции. - Т. I. - Алматы: Экономика, 2010. - С. 125-132.

4. Нижегородиев Р.М., Горидько Н.П. Принцип Хаавельмо: рост государственных расходов как инструмент стимулирования экономического подъема // Политэкономия: социальные приоритеты. Материалы Первого международного политэкономического конгресса. Т. 2. Национальные экономики в глобальном мире: Политическая экономия и экономическая политика/ Под ред. А.В. Бузгалина, М.И. Воейкова, О.Ю. Ма- медова, В.Т. Рязанова. - М.: ЛЕНАНД, 2013. - C. 109-126.

5. Нижегородиев Р. М. Современные тенденции мировой динамики (размышления над книгой Аскара Акаева) // Russian Journal of Management. - 2016. - T. 4. - Выпуск 3(21). - С. 412-415.

6. Нижегородиев P.М. Аттестация научных кадров: нерешенные проблемы // Юридическое образование и наука. - 2018. №3. - C. 29-36.

7. Нижегородиев Р.М. Экономика инфляционного разрыва // Альтернативы. 2012. — №3 (76). - С. 141-150.

8. Социально-экономические риски: диагностика причин и прогнозные сценарии нейтрализации / Под ред. В.А. Черешнева, А.И. Татаркина. — Екатеринбург: Институт экономики УрО РАН, 2010.

9. Экономическая безопасность России: уроки кризиса и перспективы роста. Т. 1 / Под ред. В.А. Черешнева, А.И. Татаркина, М.В. Федорова. - Екатеринбург: Институт экономики УрО РАН, 2012.

10. Нижегородиев Р.М., Горидько Н.П., Швец И. Ю., Рослякова Н.А. Экономическое развитие регионов: факторы, стратегии, безопасность: Научная монография. - М.: ООО «НИПКЦ Восход-А», 2018. - $336 \mathrm{c.}$

11. Глазьев С. Ю., Горидько Н. П., Нижегородиев Р.М. Критика формулы Ирвинга Фишера и иллюзии современной монетарной политики // Экономика и математические методы. - 2016. - Т. 52. - №4. - С. 3-23.

12. Goridko N.P. Influence of the Central Bank's anti-inflationary policy on Russia's economic development // Известия Уральского государственного экономического университета. - 2018. - Т. 19. - №6. C. 51-61.

13. Нижегородиев Р.М. Современная динамика рынка труда в России и барьеры на пути инновационного развития экономики// Russian Journal of Management. 2015. 一 №3. - C. 213-219.

14. Горидько Н.П., Нижегородиев Р.М. Россия на пути к цифровой экономике: ловушки и вызовы // Шаг в будущее: искусственный интеллект и цифровая экономика: Материалы 1-й Международной научнопрактической конференции. Выпуск 1. - М.: Изд. дом ГУУ, 2017. — С. 74-86. 
15. Горидько Н.П., Нижегородиев Р.М. Угрозы цифровизации и экономическая безопасность: императивы и альтернативы // Глобализация экономики и российские производственные предприятия: Материалы 17-й Международной научно-практической конференции в рамках Научного форума «Неделя инженерной экономики», 13-17 мая 2019 г., г. Новочеркасск: в 2-х ч. - Ч. 1. - Новочеркасск: Изд-во «НОК», 2019. - С. 17-26.

16. Горидько Н. П., Нижегородиев Р.М. Имитационное моделирование сценариев управления экономической динамикой в условиях нарастания внешних угроз // Национальные интересы: приоритеты и безопасность. - 2014. — №46. - С. 48-59.
17. Нижегородиеев Р. М. Импортозамещение институтов: ключевая задача обеспечения национальной безопасности // Известия Уральского государственного экономического университета. — 2016. - №4 (66). C. 5-18.

18. Нижегородиев Р. М. Парадигма неравновесия и задачи государственного управления в Российской Федерации в условиях импортозамещения институтов // Государственное управление. [Электронный ресурс] Электронный вестник. 2016. - Выпуск №58. - C. 39-53. - Режим доступа: http:// e-journal.spa.msu.ru/uploads/vestnik/2016/ vipusk_58._oktjabr_2016_g./58_2016.pdf.

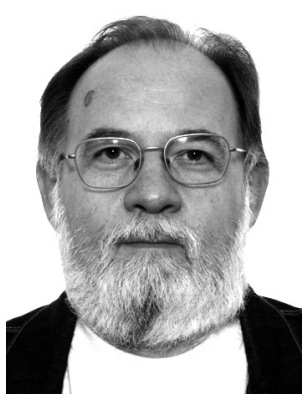

Нижегородцев Роберт Михайлович - доктор экономических наук, заведующий лабораторией Института проблем управления РАН. Специалист в области информационной экономики, экономики инноваций, макроэкономики и экономической политики, институциональной экономики. Автор более 850 научных публикаций, в том числе 33 монографий и более чем 200 статей в ведущих российских журналах.

Nizhegorodtsev Robert Mikhailovich - Doctor of Economics, Laboratory chief in the Institute of Control Sciences RAS. Majors in information economy, economics of innovations, macroeconomics and government policies, institutional economics. The author of more than 850 publications, including 33 monographs and more than 200 papers in top-level Russian journals.

117997, г. Москва, ул. Профсоюзная, 65

65 Profsoyuznaya st., 117997, Moscow, Russia

Тел.: +7 (495) 334-93-09; e-mail: bell44@rambler.ru 